\title{
PERBEDAAN KEMAMPUAN EMPATI MAHASISWA KEPERAWATAN DI PROGRAM STUDI ILMU KEPERAWATAN FAKULTAS KEDOKTERAN UGM
}

\author{
Anisa Hidayah*, Martina Sinta Kristanti**, Mariyono Sedyowinarso** \\ * Mahasiswa Program Studi IImu Keperawatan, Fakultas Kedokteran UGM \\ ** Dosen Program Studi IImu Keperawatan, Fakultas Kedokteran UGM
}

\begin{abstract}
Background: Nurses are supposed to be able to show empathy to patients. Empathy is capability to feel the emotion, thought, and condition of the patient without involving self emotion. Capability of showing empathy in nurses is built since the period of education. Every stage in nursing education at nursing study program has different learning activities and load of materials. The difference may be affected by capability of showing empathy in students.

Objective: To identify difference in empathy capability of nursing students of Faculty of Medicine UGM

Method: This was a quantitative study with cross sectional design. Samples were taken through purposive proportional sampling involving 88 nursing students at Faculty of Medicine Gadjah Mada University undergoing academic education (batch 2009 to 2012) and clinical education (batch 2007 and 2008). Empathy capability was assessed using Jefferson Scale of Physician Empathy - Nursing Student Version R (JSPE-R).

Result: Average score of empathy capability was 113.26 with standard deviation 10.45 . There was difference in empathy capability of students of batch 2007 to 2012 ( $\mathrm{p}=0.014$ ). Average score of empathy capability of the students decreased along with the duration of education. There was no difference in empathy capability based on gender $(p=0.516)$, age $(p=0.668)$, ethnic group $(p=0.167)$, and stage of education $(p=0.541)$. There was difference in score of standing in the patient shoes between academic and clinical students $(\mathrm{p}=0.022)$.

Conclusion: There was difference in empathy capability in nursing students from different batch at Faculty of Medicine UGM.
\end{abstract}

Keywords: empathy, nursing students, academic education, professional education

\section{ABSTRAK}

Latar Belakang : Perawat diharapkan dapat menunjukan sikap empati kepada pasien. Empati merupakan kemampuan merasakan perasaan, pikiran, dan kondisi pasien tanpa melibatkan emosi diri. Kemampuan empati perawat dibentuk sejak masa pendidikan menjadi perawat. Setiap tahap dalam pendidikan ners di PSIK FK UGM memiliki aktivitas pembelajaran dan beban materi yang berbeda. Perbedaan tersebut mungkin dapat mempengaruhi kemampuan empati mahasiswa.

Tujuan : Untuk mengetahui perbedaan kemampuan empati mahasiswa keperawatan antar angkatan di PSIK FK UGM. Metode : Penelitian ini adalah penelitian kuantitatif, dengan rancangan penelitian cross sectional. Sampel diambil dengan pengambilan purposive proportional sampling sebanyak 88 mahasiswa PSIK FK UGM yang menempuh pendidikan akademik (angkatan 2009 sampai 2012) dan pendidikan profesi (angkatan 2007 dan 2008). Pengukuran kemampuan empati dengan menggunakan instrumen Jefferson Scale of Physician Empathy - Nursing Student Version R (JSPE-R).

Hasil : Rata - rata nilai kemampuan empati mahasiswa PSIK FK UGM adalah 113,26 dengan standar deviasi 10,45. Terdapat perbedaan kemampuan empati angkatan 2007 hingga 2012 ( $\mathrm{p}=0,014)$. Nilai rata - rata kemampuan empati mahasiswa mengalami penurunan seiring dengan lama waktu pendidikan. Mahasiswa angkatan 2007 memiliki nilai kemampuan empati paling rendah, sedangkan angkatan 2012 memiliki nilai paling tinggi. Tidak terdapat perbedaan kemampuan empati berdasarkan

Korespondensi: Nindya Aryanty, Jl. Rajawali I No. 3, Jambi, Indonesia, 36138, Telp +6285266937383, email: nindya_aryanty@yahoo.co.id 
jenis kelamin $(p=0,516)$, usia $(p=0,668)$, suku $(p=0,167)$, dan tahap pendidikan $(p=0,541)$. Terdapat perbedaan nilai pada komponen memposisikan diri seperti pasien antara mahasiswa profesi dan akademik $(\mathrm{p}=0,022)$.

Kesimpulan : Terdapat perbedaan kemampuan empati antar angkatan mahasiswa PSIK FK UGM.

Kata Kunci : Empati, mahasiswa keperawatan

\section{PENDAHULUAN}

Perawat dituntut untuk mampu mengidentifikasi dan memecahkan masalah pasien. Keahlian dalam membina hubungan interpersonal diperlukan dalam membangun kepercayaan antara perawat dan pasien. ${ }^{1}$ Maka dari itu, seorang perawat sangat penting untuk memiliki sikap empati dalam melakukan tindakan keperawatan kepada pasien $^{2}$. Sikap empati perawat yang tinggi dapat memberikan kepuasan pasien dalam menerima tindakan keperawatan. ${ }^{3}$

Perilaku yang diberikan oleh perawat kepada pasien berbeda - beda, hal tersebut dipengaruhi oleh tipe empati yang dimiliki oleh setiap perawat. Kemampuan empati yang diberikan oleh perawat, salah satunya tergantung oleh pembentukan diri perawat tentang empati. ${ }^{4}$ Pembentukan kemampuan empati dipengaruhi oleh jenis kelamin, pengalaman klinik, lama pendidikan, pola asuh, status sosial ekonomi dan keadaan emosional seseorang. ${ }^{5}$ Proses pembelajaran, tugas akademik, dan tanggung jawab sebagai mahasiswa merupakan salah satu stressor tersendiri bagi mahasiswa. ${ }^{6}$ Perubahan dari idealism menjadi realism mengenai tindakan pada pasien dapat mempengaruhi perasaan mahasiswa. Salah satu penelitian diperoleh hasil bahwa nilai empati mahasiswa mengalami penurunan selama menempuh perkuliahan. ${ }^{7}$

Program Studi Ilmu Keperawatan FK UGM merupakan institusi pendidikan yang menyelenggarakan pendidikan ners, terdiri dari tahap akademik dan tahap profesi. Setiap angkatan memiliki aktivitas pembelajaran dan beban materi yang berbeda, sehingga kemampuan empati mahasiswa mungkin terdapat perbedaan. Tujuan dari penelitian ini adalah untuk mengetahui perbedaan kemampuan empati mahasiswa keperawatan di PSIK FK UGM.

\section{METODE}

Jenis penelitian ini adalah penelitian deskriptif komparatif. Pendekatan yang digunakan adalah pendekatan kuantitatif dengan rancangan cross sectional. Penelitian dilakukan pada bulan Oktober November 2012 pada 88 mahasiswa PSIK FK UGM angkatan 2007 - 2012 dengan menggunakan teknik purposive proportional sampling.

Pengukuran kemampuan empati mahasiswa menggunakan instrumen Jefferson Scale of Physician Empathy Nursing Student Version R (JSPE-R),merupakan instumen yang dikembangkan oleh $\mathrm{M}$. Hojat et al dari Jefferson Medical College di Philadelphia. Komponen JSPE-R meliputi perspective taking, compassionate care dan standing in the patient's shoes. Kuesioner JSPE-R terdiri dari 20 item dengan jawaban skala likert dari 1 (sangat tidak setuju) sampai 7 (sangat setuju). Item favourable dan unfavourable masing - masing terdapat 10 item. Nilai JSPE-R berkisar dari nilai minimum 20 sampai nilai maksimum 140. Semakin tinggi total nilai mengindikasikan semakin baik pula kemampuan empati yang dimiliki. ${ }^{8}$

Uji validitas dan reliabilitas telah dilakukan pada 60 orang. Item yang dinyatakan valid berjumlah 17 item dari 20 item, nilai validitas berkisar antara 0,315 0,671, dan hasil reliabilitas instrumen yaitu 0,710 . Peneliti tetap menggunakan 20 item dikarenakan item tersebut merupakan pernyataan penting dalam pengukuran kemampuan empati mahasiswa.

Uji komparasi krukall wallis untuk mengetahui perbedaan kemampuan empati berdasarkan tahun angkatan dan dilanjutkan uji posthoc. Uji mann whitney dilakukan untuk mengetahui perbedaan kemampuan empati berdasarkan jenis kelamin, komponen compassionate care dan komponen standing in the patient shoes. Perbedaan kemampuan empati berdasarkan umur 
responden dianalisis menggunakan uji one way ANOVA. Uji t tidak berpasangan digunakan untuk mengetahui perbedaan kemampuan empati berdasarkan suku, tahap pendidikan dan komponen perspective taking antara mahasiswa akademik dan profesi.

\section{HASIL PENELITIAN}

Responden adalah mahasiswa keperawatan di PSIK FK UGM terdiri dari $4(5,5 \%)$ orang dari angkatan 2007, $9(10,2 \%)$ orang dari angkatan $2008,18(20,5 \%)$ orang dari angkatan 2009 dan 2010, 20 (22,7\%) orang dari angkatan 2011 dan 19 (21,6\%) orang dari angkatan 2012. Angkatan 2007 dan 2008 merupakan mahasiswa yang sedang menempuh pendidikan profesi di rumah sakit. Sedangkan angkatan 2009 sampai 2011 adalah mahasiswa yang masih menempuh pendidikan akademik. Rentang umur responden yaitu 17 sampai 23 tahun. Sebagian besar mahasiswa adalah perempuan yaitu sejumlah 69 orang $(78,4 \%)$. Berdasarkan penggolongan umur, responden paling banyak berumur 20 tahun yaitu 24 orang (27,3\%). Suku Jawa merupakan suku yang paling banyak daripada suku selain Jawa, yaitu $76(86,4 \%)$.
Hasil pengukuran kemampuan empati mahasiswa PSIK FK UGM angkatan 2007 sampai 2012 dapat dilihat pada tabel 1. Rata - rata nilai kemampuan empati mahasiswa PSIK FK UGM adalah 113,26 dengan standar deviasi 10,448 . Terdapat perbedaan kemampuan empati antar angkatan secara statistik dengan nilai signifikansi 0,014 ( $p<0,05)$. Mahasiswa angkatan 2007 memiliki nilai kemampuan empati paling rendah (106), sedangkan angkatan 2012 memiliki nilai paling tinggi (116,05). Angkatan 2011 memiliki nilai rerata paling rendah pada tahap akademik yaitu 107,75. Angkatan 2008 dan 2009 memiliki nilai rerata dalam angka yang relatif sama.

Uji post hoc dilakukan lebih lanjut untuk mengetahui kelompok angkatan yang mempunyai perbedaan nilai kemampuan empati. Berdasarkan tabel 2, hasil uji post hoc dapat diketahui bahwa perbedaan rerata kemampuan empati terdapat pada 3 kelompok, yaitu angkatan 2009 dan 2011 ( $\mathrm{p}=0,008)$, angkatan 2010 dan 2011 $(\mathrm{p}=0,01)$, angkatan 2011 dan $2012(\mathrm{p}=0,001)$. Tidak terdapat perbedaan rata - rata kemampuan empati pada kelompok uji tanpa angkatan 2011.

Tabel 1. Uji komparasi kemampuan empati mahasiswa angkatan 2007-2012 ( $\mathrm{n}=88$ )

\begin{tabular}{ccccc} 
Angkatan & $\mathbf{N}$ & Mean \pm SD & Median (Min-Max) & $p$ \\
\hline $2007-2012$ & 88 & $113,26 \pm 10,45$ & $113,5(82-134)$ & \\
\hline 2007 & 4 & $106 \pm 13,74$ & $106,5(91-120)$ & \\
2008 & 9 & $114,11 \pm 8,08$ & $116(102-126)$ & \\
2009 & 18 & $114,94 \pm 10,45$ & $115(89-131)$ & 0,014 \\
2010 & 18 & $115,94 \pm 12,90$ & $116,5(82-134)$ & \\
2011 & 20 & $107,75 \pm 6,41$ & $110(93-117)$ & \\
2012 & 19 & $116,05 \pm 9,97$ & $117(87-129)$ & \\
\hline
\end{tabular}


Karakteristik responden meliputi jenis kelamin, usia, suku dan tahap pendidikan. Uji komparatif kemampuan empati dilakukan berdasarkan karakteristik responden tersebut dapat dilihat pada tabel 3. Secara statistik tidak ada perbedaan kemampuan empati antara mahasiswa laki - laki dan perempuan $(\mathrm{p}=0,516)$, usia responden $(\mathrm{p}=0,668)$, suku $(0,167)$ dan tahap pendidikan $(0,541)$. Nilai rata - rata kemampuan empati mahasiswa perempuan lebih tinggi daripada mahasiswa laki - laki. Nilai rata - rata kemampuan empati setiap umur berada pada nilai yang hampir sama, yaitu 108 - 114 .

Komponen perspective taking $(\mathrm{p}=0,473)$ dan compassionate care $(\mathrm{p}=0,062)$ tidak terdapat perbedaan yang signifikan antara mahasiswa akademik dan profesi. Sedangkan komponen ketiga yaitu standing in the patient shoes memiliki perbedaan yang signifikan antara mahasiswa tahap akademik dan tahap profesi, dengan $\mathrm{p}=0,022$ $(p<0,05)$. Perbedaan tersebut dapat dilihat dari rata rata nilai komponen empati ketiga pada tahap akademik lebih rendah daripada tahap profesi.
Tabel 2. Uji post hoc perbedaan kemampuan empati antar angkatan 2007 sampai 2012

\begin{tabular}{cccc} 
No & \multicolumn{2}{c}{ Perbedaan Nilai Empati antara } & \multirow{2}{*}{$p$} \\
\cline { 2 - 3 } & $\begin{array}{c}\text { Angkatan } \\
\text { (mean) }\end{array}$ & $\begin{array}{c}\text { Angkatan } \\
\text { (mean) }\end{array}$ & \\
\hline 1 & $2007(106)$ & $2008(114,11)$ & 0,280 \\
2 & $2007(106)$ & $2009(114,94)$ & 0,267 \\
3 & $2007(106)$ & $2010(115,94)$ & 0,201 \\
4 & $2007(106)$ & $2011(107,75)$ & 0,969 \\
5 & $2007(106)$ & $2012(116,05)$ & 0,155 \\
6 & $2008(114,11)$ & $2009(114,94)$ & 0,777 \\
7 & $2008(114,11)$ & $2010(115,94)$ & 0,537 \\
8 & $2008(114,11)$ & $2011(107,75)$ & 0,053 \\
9 & $2008(114,11)$ & $2012(116,05)$ & 0,375 \\
10 & $2009(114,94)$ & $2010(115,94)$ & 0,716 \\
11 & $2009(114,94)$ & $2011(107,75)$ & $0,008^{*}$ \\
12 & $2009(114,94)$ & $2012(116,05)$ & 0,563 \\
13 & $2010(115,94)$ & $2011(107,75)$ & $0,010^{*}$ \\
14 & $2010(115,94)$ & $2012(116,05)$ & 0,964 \\
15 & $2011(107,75)$ & $2012(116,05)$ & $0,001^{*}$ \\
\hline$* p<0,05$ & &
\end{tabular}

Tabel 3. Uji komparatif kemampuan empati berdasarkan karakteristik responden $(n=88)$

\begin{tabular}{|c|c|c|c|c|c|}
\hline Keterangan & $\mathbf{N}$ & Mean \pm SD & $\begin{array}{l}\text { Median } \\
\text { (Min-Max) }\end{array}$ & $p$ & $\begin{array}{c}\text { CI } \\
(95 \%)\end{array}$ \\
\hline $\begin{array}{l}\text { Jenis Kelamin } \\
\text { Perempuan } \\
\text { Laki-laki }\end{array}$ & $\begin{array}{l}69 \\
19\end{array}$ & $\begin{array}{c}113,97 \pm 9,72 \\
110,68 \pm 12,72\end{array}$ & $\begin{array}{l}113(82-134) \\
115(87-127)\end{array}$ & 0,516 & \\
\hline $\begin{array}{l}\text { Usia } \\
\qquad 17 \text { tahun } \\
18 \text { tahun } \\
19 \text { tahun } \\
20 \text { tahun } \\
21 \text { tahun } \\
22 \text { tahun } \\
23 \text { tahun }\end{array}$ & $\begin{array}{c}3 \\
19 \\
14 \\
24 \\
18 \\
5 \\
5\end{array}$ & $\begin{array}{c}112 \pm 5 \\
114,74 \pm 11,69 \\
108,79 \pm 7,43 \\
114,38 \pm 11,2 \\
114,83 \pm 10,78 \\
110 \pm 7,07 \\
113,20 \pm 13,79\end{array}$ & $\begin{array}{c}112(107-117) \\
117(87-129) \\
109,5(96-125) \\
114(82-134) \\
116,5(89-131) \\
110(102-118) \\
115(91-126)\end{array}$ & 0,668 & \\
\hline $\begin{array}{l}\text { Suku } \\
\text { Jawa } \\
\text { Non Jawa }\end{array}$ & $\begin{array}{l}74 \\
14\end{array}$ & $\begin{array}{c}113,93 \pm 9,62 \\
109,71 \pm 13,95\end{array}$ & $\begin{array}{l}114,5(89-134) \\
111,5(82-129)\end{array}$ & 0,167 & $\begin{array}{c}(-1,803) \text { s.d. } \\
10.239\end{array}$ \\
\hline $\begin{array}{c}\text { Tahap Pendidikan } \\
\text { Akademik } \\
\text { Profesi }\end{array}$ & $\begin{array}{l}75 \\
13\end{array}$ & $\begin{array}{l}113,55 \pm 10,52 \\
111,62 \pm 10,29\end{array}$ & $\begin{array}{l}113(82-134) \\
115(91-126)\end{array}$ & 0,541 & $\begin{array}{c}(-4,331) \text { s.d. } \\
8,194\end{array}$ \\
\hline
\end{tabular}


Anisa Hidayah dkk, Perbedaan Kemampuan Empati Mahasiswa Keperawatan di Program Studi IImu Keperawatan Fakultas Kedokteran UGM

Tabel 4. Uji perbedaan komponen kemampuan empati antara mahasiswa tahap akademik dan profesi $(\mathrm{n}=88)$

\begin{tabular}{|c|c|c|c|c|c|c|c|}
\hline & \multirow[b]{2}{*}{ Komponen } & \multicolumn{2}{|c|}{ Akademik (n=74) } & \multicolumn{2}{|c|}{ Profesi $(n=14)$} & \multirow[b]{2}{*}{$p$} & \multirow[b]{2}{*}{$\begin{array}{c}\text { CI } \\
(95 \%)\end{array}$} \\
\hline & & $\begin{array}{l}\text { Mean } \\
\text { (SD) }\end{array}$ & $\begin{array}{c}\text { Median } \\
\text { (Min-Max) }\end{array}$ & $\begin{array}{l}\text { Mean } \\
\text { (SD) }\end{array}$ & $\begin{array}{c}\text { Median } \\
\text { (Min-Max) }\end{array}$ & & \\
\hline 1. & Perspective taking & $\begin{array}{l}61,01 \\
(5,38)\end{array}$ & $\begin{array}{c}62 \\
(47-70)\end{array}$ & $\begin{array}{l}59,85 \\
(5,44)\end{array}$ & $\begin{array}{c}62 \\
(51-70)\end{array}$ & 0,473 & $\begin{array}{l}(-2,052) \\
\text { S.d.4,386 }\end{array}$ \\
\hline 2. & $\begin{array}{l}\text { Compassionate } \\
\text { care }\end{array}$ & $\begin{array}{l}44,41 \\
(6,34)\end{array}$ & $\begin{array}{c}45 \\
(18-56)\end{array}$ & $\begin{array}{l}41,85 \\
(5,29)\end{array}$ & $\begin{array}{c}40 \\
(33-51)\end{array}$ & 0,062 & - \\
\hline 3. & $\begin{array}{l}\text { Standing in the } \\
\text { patient's shoes }\end{array}$ & $\begin{array}{c}8,12 \\
(2,53)\end{array}$ & $\begin{array}{c}8 \\
(3-14)\end{array}$ & $\begin{array}{c}9,92 \\
(2,29)\end{array}$ & $\begin{array}{c}11 \\
(6-13)\end{array}$ & 0,022 & - \\
\hline
\end{tabular}

\section{PEMBAHASAN}

Perbedaan Kemampuan Empati Mahasiswa PSIK FK UGM

Nilai rata - rata kemampuan empati mengalami penurunan seiring dengan peningkatan lama waktu pendidikan. Hasil penelitian ini didukung oleh penelitian Chen et al ${ }^{9}$ dengan meode cross sectional pada mahasiswa kesehatan. Hasil penelitian tersebut adalah nilai kemampuan empati mahasiswa kesehatan tingkat akhir memiliki kemampuan empati paling rendah dan mahasiswa tingkat pertama memiliki kemampuan empati paling tinggi.

Peran pengajar antara lain sebagai sumber informasi, evaluator, fasilitator, dan berperan sebagai pemberi contoh role model yang baik. Kegiatan pembelajaran yang telah diterapkan di PSIK FK UGM meliputi tutorial, kuliah pakar, dan skills lab. Role model secara tidak langsung dapat mempengaruhi kemampuan empati mahasiswa. ${ }^{10}$ Kemampuan empati mahasiswa mudah terpengaruh dikarenakan hidden curriculum dalam proses pembelajaran. ${ }^{11}$ Nilai idealisme, entusiasme, dan rasa kemanusiaan sangat diperlihatkan pada awal pendidikan kesehatan. Tetapi, perasaan tersebut tergeser oleh pendidikan kesehatan dan pengalaman klinik. ${ }^{12}$

Penyebab lain penurunan kemampuan empati yaitu terkait masalah dukungan sosial. Pada saat mahasiswa memiliki tugas akademik maupun klinik yang berlebihan, mahasiswa mengalami penurunan komunikasi dengan keluarga dan dukungan sosial. ${ }^{13}$ Mahasiswa melakukan kegiatan kerja yang pada jam yang terlalu panjang, sehingga mengalami penurunan waktu tidur, sehingga waktu untuk bersantai pun berkurang. ${ }^{14}$

\section{Perbedaan Kemampuan Empati Berdasarkan Karakteristik Responden}

Tidak terdapat perbedaan kemampuan empati antara laki - laki dan perempuan. Hasil tersebut sesuai dengan penelitian yang dilakukan pada mahasiswa kedokteran oleh Hojat et al, ${ }^{15}$ dimana tidak terdapat perbedaan nilai kemampuan empati laki - laki dan perempuan $(p=0,08)$. Teori yang dikemukakan oleh Cooper dan Sawaf ${ }^{16}$ bahwa laki - laki dan perempuan dapat mengembangkan kemampuan empati bersama - sama melalui proses pembelajaran.

Mahasiswa laki-laki memiliki nilai yang lebih rendah dibandingkan dengan perempuan. Perempuan lebih peka terhadap perasaan yang diungkapkan oranglain ${ }^{15}$, mudah dalam mengungkapkan ekspresi emosi daripada laki-laki ${ }^{9}$, lebih suka mengembangkan hubungan interpersonal, memberikan dukungan emosional, berperikemanusiaan, dan menunjukan sikap yang lebih peduli. Laki-laki cenderung menunjukan sikap yang menghakimi, lebih dominan, mandiri dan menguasai. ${ }^{17}$ Salah satu bukti bahwa jenis kelamin mempengaruhi kemampuan empati adalah tenaga kesehatan perempuan menghabiskan lebih banyak waktu dengan pasien mereka. ${ }^{18}$ 
Tidak terdapat perbedaan kemampuan empati dalam setiap usia. Penelitian Garaigordobil mengemukakan bahwa , nilai kemampuan empati relatif sama dalam setiap umur $(\mathrm{p}=0,09) .{ }^{19}$ Nunes et al mengungkapkan bahwa mahasiswa kurang dari 21 tahun tidak memiliki perbedaan kemampuan empati dengan mahasiswa umur sedang (22 - 27 tahun).

Tidak terdapat perbedaan nilai kemampuan kemampuan mahasiswa dari suku Jawa dan non Jawa. Hal tersebut dijelaskan bahwa instrumen JSPE digunakan untuk mengetahui kemampuan empati pada mahasiswa kesehatan, tidak untuk mengukur empati antar suku. ${ }^{20}$ Lebih lanjut dijelaskan oleh Novianti ${ }^{21}$ bahwa tidak terdapat perbedaan culture shock antara mahasiswa suku jawa dan non Jawa di PSIK FK UGM. Sebuah komunitas yang didalamnya terdiri dari beberapa kelompok berbeda dapat saling mengerti dan memahami perasaan sesama anggota kelompok seiring dengan lama waktu berinteraksi bersama dalam kelompok. ${ }^{22}$

Mahasiswa tahap akademik dan profesi tidak terdapat perbedaan kemampuan empati. Faktor yang dapat mempengaruhi perkembangan empati individu adalah interaksi sosial bersama individu yang lain. Agar dapat diterima oleh orang lain, individu menyesuaikan perilaku mereka dengan kebutuhan, pilihan dan harapan orang lain. ${ }^{23}$ Mahasiswa akademik mendapatkan pembelajaran melalui berbagai cara yaitu kuliah pakar, tutorial, diskusi bersama kelompok dan seminar. ${ }^{24}$ Pembelajaran tersebut menuntut mahasiswa untuk berfikir kritis agar dapat menyesuaikan dengan lingkungan. Sedangkan pada mahasiswa profesi telah melaksanakan KKN (Kuliah Kerja Nyata) serta kegiatan profesi di komunitas, dimana pembelajaran secara langsung bersama masyarakat. Kegiatan pendidikan tersebut merupakan bentuk interaksi sosial mahasiswa bersama orang lain.

\section{Perbedaan Komponen Kemampuan Empati antara Mahasiswa Tahap Akademik dan Profesi}

Tidak Terdapat perbedaan komponen perspective taking antara mahasiswa akdemik dan profesi. Hasil tersebut sesuai dengan penelitian Gonullu dan Oztuna ${ }^{25}$ bahwa tidak terdapat perbedaan pada komponen perspective taking $(\mathrm{p}=0,341)$. Komponen ini dapat dikembangkan dalam kehidupan sehari - hari. Mahasiswa mampu untuk mengembangkan kemampuan untuk berfikir dan membayangkan perasaan orang lain dalam setiap hari, sehingga antara tahap profesi dan akademik memiliki nilai yang hampir sama. ${ }^{22}$

Compassionate care yaitu pengalaman - pengalaman yang berhubungan dengan perasaan iba, rasa mengasihi, kehangatan dan perhatian terhadap kemalangan orang lain. Komponen kedua ini membutuhkan perasaan emosional dalam berinteraksi. ${ }^{22}$ Mahasiswa pertama dan tahap akhir pendidikan kesehatan memiliki perasaan emosional yang sama. ${ }^{26}$

Komponen standing in the patient's shoes dimana seseorang mampu untuk melakukan tindakan secara langsung dalam memposisikan diri seperti pasien. Komponen ini lebih berfokus pada perilaku seseorang dalam mengekspresikan perasaanya. ${ }^{22}$ Mahasiswa profesi sudah memiliki pengalaman klinik di rumah sakit dan mempraktikan ilmu yang sudah didapatkan selama menempuh tahap akademik. Sehingga mahasiswa profesi dapat mengekspresikan perasaan empati secara langsung kepada pasien.

\section{KESIMPULAN}

Terdapat perbedaan kemampuan empati mahasiswa keperawatan antar angkatan. Terjadi penurunan nilai kemampuan empati seiring dengan peningkatan lama pendidikan. Nilai rata - rata kemampuan empati mahasiswa PSIK FK UGM adalah 113,26. Tidak terdapat perbedaan kemampuan empati berdasarkan jenis kelamin, usia, suku dan tahap pendidikan.

Perbedaan nilai pada komponen kemampuan empati antara mahasiswa profesi dan akademik terletak pada komponen ketiga yaitu standing in the patient shoes.

\section{SARAN}

Institusi pendidikan perlu ikut serta dalam menjaga kemampuan empati mahasiswa. Mahasiswa diharapkan dapat menumbuhkan kemampuan empati dengan meningkatkan kepedulian dalam interaksi sosial. Bagi peneliti selanjutnya, melakukan penelitian mengenai kemampuan empati mahasiswa dengan menambah metode kualitatif agar data yang didapatkan lebih kompleks. Instrumen penelitian JSPE-R dapat 
dilakukan uji validitas ulang untuk keakuratan data yang diambil.

\section{DAFTAR PUSTAKA}

1. Morrison, P \& Burnard, P. Caring $\mathcal{E}$ Communicating: Hubungan Ineterpersonal dalam Keperawatan. 2002. Jakarta: EGC

2. Fatimah, Elita, V., Wahyuni, S.Gambaran Tipe Empati Perawat Jiwa Di Rumah Sakit Jiwa Tampai Pekanbaru. Jurnal Keperawatan. September 2010; 3(2): 88 - 97

3. Fatoni, M.Hubungan Persepsi dengan Kepuasan Pasien tentang Sikap Empati Perawat di Ruang Rawat Inap RSUD Sleman [Skripsi]. PSIK FK UGM. Yogyakarta; 2007.

4. Diana, L.M.A. Hubungan antara Pengendalian Emosi dengan Empati Perawat pada Pasien di BPKM RSU "Ngudi Waluyo" Wlingi Kabupaten Blitar [Skripsi] Yogyakarta : PSIK FK UGM; 2004

5. Hojat, M., Louis, D.Z., Maxwell, K., Gonnella, J.S.The Jefferson Scale of Empathy (JSE): An Update.Health Policy Newsletter.2011; 24(2)

6. Michaelec, B.An Assessment of Medical School Stressor on Preclinical Students Level of Clinical Empathy.Current Psychology 2010; 29:210-21

7. Nunes, P., Stella, W., Sa, B., Stevenson,K.A Study of Empathy Decline in Students from Five Health Disciplines during Their First Year of Training. International Journal of Medical Education. 2011; 2:12-17

8. Vallabh, K.Psychometrics of the student version of the Jefferson Scale of Physician Empathy (JSPE-S) in final-year medical students in Johannesburg. SAJBL: Article December 2011; 4(2)

9. Chen, D., Lew, R. Hershman, W., Orlander, J.A Crosssectional Measurement of Medical Student Empathy.Journal General Internal Medicine 2007; 22(10): 1434-8

10. Stojilkovi, S.,Djigi, G.,Zlatkovi, B.Empathy and Teacher's Roles.Social and Behavioral Sciences 2012; 69: $960-966$

11. Neuman, et al.Empathy Decline and Its Reasons: A Systematic Review of Studies with Medical Students and Residents.Academic Medicine 2011; 86(8)

12. Stratton, T.D., Saunders, J.A.,Elam, C.L.Changes in Medical Student's Emotional Intelligence: An Exploratory Study.Teaching and Learning in Medicine 2008; 20 (3)

13. Bellini, L.M., Baime, M., Shea, J.AVariation of Mood and Empathy During Internship.JAMA 2009; 287(23):3143-3146
14. Lockley, S.W., et al.Effects of Health Care Provider Work Hours and Sleep Deprivation on Safety and Performance. The Joint Commission Journal on Quality and Patient Safety 2007; 33(11).

15. Hojat, M., Gonella, J.S., Nasca, T.J., Mangione, S., Vergare, M. Magee, M. Phisician Empathy: Definition, Components, Measurement and Relationship to Gender and Specialty.Am J Psychiatry. 2002: 159-9

16. Cooper, R., Sawaf. H.Executive EQ.Kecerdasan Emosional dalam Kepemimpinan dan Organisasi. Jakarta: PT Gramedia Pustaka Utama. 1999.

17. Magalhaes, E., Salgueira, A.P.,Costa, P.,Costa, M.J.Empathy in Senior Year and First Year Medical Students:a Cross-sectional Study. BMC Medical Education. 2011; 11: 52

18. Bertakis KD, Helms LJ, Callahan EJ, Azari R, Robbins JA.The influence of gender on physician practice style. Med Care 1995;33:407-16

19. Garaigordobil, M.A Comparative Analysis of Empathy in Childhood and Adolescence: Gender Differences and Associated Socio-emotional Variables. International Journal of Psychology and Psychological Therapy 2009; 9(2): 217-235

20. Hojat, M. et al.The Devil is in The Third Year: A Longitudinal Study of Erosion of Empathy in Medical School.Academic Medicine 2009; 84 (9).

21. Novianti, D.Faktor - Faktor yang Mempengaruhi Culture Shock pada Mahasiswa Baru Angkatan 2008 PSIK FK UGM [Skripsi]. PSIK FK UGM. Yogyakarta; 2009.

22. Taufik.Empati Pendekatan Psikologi Sosial. RajaGrafindo Persada; 2012 Jakarta.

23. Picket, P.L., Gardner, W.L., Knowles., M.Getting a Cue: The Need to Belong and Enhanced Sensitivity to Social Cues.Personality and Social Psychology Bulletin. 2004; 30 : 1095-1107

24. PSIK UGM.Panduan Akademik TA 2011/2012.2010. PSIK FK UGM. Yogyakarta.

25. Gonullu, I., Oztunaa, D.A Turkish Adaptation of the Student Version of the Jefferson Scale of Physician Empathy.Marmara Medical Journal 2012; 25:87-92

26. Dehning, S.,Girma, E.,Gasperi, S.,Meyer, S.Tesfaye, M.,Siebeck, M.Comparative Cross-Sectional Study of Empathy Among First Year and Final Year Medical Students in Jimma University, Ethiopia: Steady State of the Heart and Opening of the Eyes.BMC Medical Education 2012;12:3 